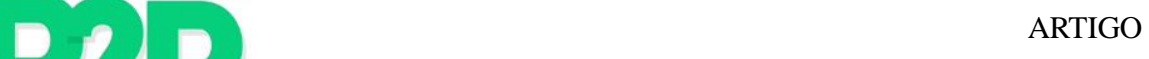

\title{
AMAZÔNIA E O DESAFIO DA SUSTENTABILIDADE: REFLEXÕES A PARTIR DA CONSTRUÇÃO DO MARCO ESTRATÉGICO DO PROJETO JUTAÍ NA RESERVA EXTRATIVISTA VERDE PARA SEMPRE
}

\author{
Elias Santos Serejo \\ Mestrando do Programa de Pós-Graduação em Comunicação, Linguagens e Cultura (PPGCLC) \\ Universidade da Amazônia (Unama) \\ Danila Cal \\ Professora do Programa de Pós-Graduação em Comunicação, Linguagens e Cultura (PPGCLC) \\ Universidade da Amazônia (Unama)
}

\begin{abstract}
Resumo
Este artigo traz reflexões sobre o processo de elaboração das diretrizes que nortearam as ações da comunidade Itapéua na implementação do manejo florestal comunitário na Reserva Extrativista Verde para Sempre no município de Porto de Moz (Pará). O objetivo dessa ação é desenvolver a cadeia produtiva sustentável da madeira na reserva. O texto foca no planejamento organizacional intitulado Marco Estratégico que trabalha noções de organização coletiva e que guiará as ações de tomadas de decisões dos moradores da reserva das comunidades durante as atividades relacionadas ao manejo florestal. Para isso, faz-se necessário apresentar o panorama contemporâneo da sustentabilidade na Amazônia e os desafios de realizar a gestão florestal em regiões de conflitos agrários. Como referencial metodológico, adotou-se a análise documental e a realização de entrevistas com técnicos e com moradores. As conclusões apontam para a proficuidade do modelo adotado para sustentabilidade da floresta e dos sujeitos que nela habitam.
\end{abstract}

Palavras-chave

Marco estratégico. Manejo florestal. Unidades de Conservação. Sustentabilidade. Comunidades tradicionais.

\section{AMAZONAND THE CHALLENGE OF SUSTAINABILITY: REFLECTIONS FROM THE CONSTRUCTION OF THE STRATEGIC FRAMEWORK OF JUTAÍ PROJECT ON EXTRACTIVE RESERVE VERDE PARA SEMPRE}

\begin{abstract}
This article reflects on the process of preparing guidelines that guided Itapéua community actions in the implementation of community forestry in the Extractive Reserve Verde para Sempre in the municipality of Porto de Moz (Pará). The purpose of this action is to develop a sustainable supply chain of wood in the region. The text focuses on organizational design titled Marco Estratégico (Strategic Framework) working notions of collective organization and to guide decision-making actions of the residents of the reserve communities in activities related to forest management. For this, it is necessary to present the contemporary view of sustainability in the Amazon and the challenges of doing forest management in regions of agrarian conflicts. As the methodological framework, was adopted the document analysis and interviews with experts and residents. The findings point to the usefulness of the model adopted for forest sustainability and subjects that dwell therein.
\end{abstract}

Keywords

Strategic Framework. Forest Management. Conservation Units. Sustainability. Traditional Communities. 


\section{Introdução}

Existem grandes desafios para a efetivação do uso dos recursos naturais da Amazônia de forma sustentável por moradores tradicionais das florestas. Isso porque, em geral, as populações inseridas no contexto das florestas nativas ainda estão expostas a um baixo nível de apoio em termos de políticas públicas básicas. Boa parte dessas populações luta pela efetivação do manejo florestal sustentável e busca parcerias como forma de tornar o extrativismo uma alternativa de geração de renda e bem-estar social. No cerne dessa discussão nascem novos olhares para a floresta, desta vez com uma visão voltada para aqueles que vivem dela e para ela.

O objetivo deste artigo é refletir sobre planejamento estratégico e iniciativa metodológica utilizada pela organização social Instituto Floresta Tropical - IFT em comunidades tradicionais da Amazônia, especificamente na Reserva Extrativista (Resex) Verde Para Sempre, localizada no município de Porto de Moz (Pará). Tal iniciativa fomenta o debate sobre a participação coletiva na construção de normas, regras, missões e valores de um grupo de extrativistas florestais que mora em uma Unidade de Conservação. O IFT é uma Organização da Sociedade Civil de Interesse Público (Oscip) ${ }^{1}$ brasileira que atua na Amazônia há 21 anos, cuja missão é promover a adoção de boas práticas de manejo florestal, contribuindo para a conservação dos recursos naturais e a melhoria da qualidade de vida da população. Em 2015, iniciou a realização de um trabalho na comunidade Itapéua, localizada na Reserva Extrativista Verde Para Sempre com o objetivo de produzir, a partir das experiências dos moradores da Unidade de Conversação, um produto comunicacional que registrasse os anseios e compromissos dos comunitários em relação ao manejo florestal.

O trabalho, intitulado Marco Estratégico, idealizado por meio de consultoria especializada em organização social comunitária, despertou reflexões entre os participantes sobre os modos de produção sustentável. Há mais de 10 anos as populações residentes na Resex lutam para garantir o direito ao uso dos recursos florestais para fins comerciais de pequena escala, ou seja, de forma comunitária. Contudo, em virtude de vários fatores que incluem o isolamento geográfico Itapéua está localizada cerca de quatro horas de viagem sob rios saindo da sede municipal, Porto

\footnotetext{
${ }^{1}$ A expressão Oscip surgiu em 1998 quando o governo sentiu necessidade de distinguir, entre as milhares de Organizações NãoGovernamentais (Ong) existentes no Brasil, quais são as que buscam o benefício público e têm representatividade junto a segmentos da sociedade civil. Para isso, foi criada uma lei que estipula uma série de normas que devem ser atendidas pelas Ong's que pretendem ser consideradas Oscip. Ao se transformar em Oscip, uma organização passa a ser considerada idônea para fazer parcerias com o governo (IPEA, 2013).
} 
de Moz; a baixa escolaridade - os manejadores possuem dificuldades em leitura e escrita, muitos apenas assinam o nome; e ao estado de extrema pobreza que se encontra, os manejadores necessitam ainda de apoio externo para aprimorar a gestão do negócio.

A partir dessa tensão entre a sustentabilidade da floresta e dos sujeitos que vivem nesse contexto, buscamos analisar neste artigo o processo de construção do Marco Estratégico e do projeto comunitário Jutaí, que busca organizar diretrizes para o manejo de madeira na Resex Verde para Sempre. Como referencial metodológico, apoiamo-nos na pesquisa documental e em na realização de entrevistas com atores sociais, ligados ao IFT, e com residentes na reserva. Foram analisados todos os documentos produzidos sobre a construção do Marco Estratégico na Resex estudada e realizadas sete entrevistas no período de 24 de fevereiro de 2015 a 06 de fevereiro de 2016.

Marcado pelos conflitos agrários, Porto de Moz é um dos municípios paraenses com os mais baixos índices de desenvolvimento humano, com $0,503^{2}$. A ação de madeireiros, fazendeiros, grileiros e especuladores imobiliários, resultam em mortes e ocasionam a saída de famílias de suas terras. Este quadro alarmante foi instalado no município com a intensificação da exploração madeireira após a chegada das serrarias. De acordo com Salgado et al, citado por Bittencourt (2003), outro fator que impulsionou este cenário foi o esgotamento das espécies exploradas na várzea, a partir disso a extração de madeira passou a ser realizada em uma distância bem maior dos rios, incluindo a utilização de maquinário pesado. A região sofre com ações de degradação dos ecossistemas locais e prejuízos ambientais significativos (BITTENCOURT, 2003).

Uma forma de atender às necessidades das populações locais - e talvez reverter essa situação - por meio da geração de renda e benefícios sociais é a atividade do manejo florestal, a qual é baseada nos princípios da sustentabilidade. A exploração dos recursos florestais é parte da rotina produtiva da comunidade Itapéua e vem sendo realizada há gerações. O manejo florestal sustentável é visto por um grupo de moradores da comunidade Itapéua como gerador de renda, emprego e capacitação de mão de obra, além de ser um meio legal de fornecimento de produtos florestais ao comércio local e regional, e para o consumo próprio das famílias.

As discussões resultaram num produto comunicacional entregue à Associação de Desenvolvimento Sustentável dos Produtores Agroextrativista da Comunidade Itapéua, entidade

2 Segundo dados do IBGE de índice de desenvolvimento humano municipal divulgados em 2010. Disponível em: ttp://www.cidades.ibge.gov.br/comparamun/compara.php?lang=\&lista=uf\&coduf=15\&idtema=118\&codv=V01\# 
jurídica detentora do Plano de Manejo Florestal Sustentável ${ }^{3}$. A publicação contém a missão, os valores, o histórico, a visão de futuro e localização do empreendimento comunitário intitulado Projeto Jutaí. Foram necessárias oficinas, reuniões e encontros de sensibilização para apresentação das diretrizes e metodologias que seriam realizadas para construção do Marco Estratégico, cujos detalhes encontram-se ao longo deste artigo. A publicação foi construída coletivamente pelos moradores e sistematizada pela equipe técnica do IFT. O Projeto Jutaí é um empreendimento comunitário de uso comercial da floresta pautado na sustentabilidade ambiental, econômica e social, fruto dos esforços das populações tradicionais que vivem na floresta. Formado por comunitários que moram na Resex, o empreendimento dá os primeiros passos para a exploração da madeira licenciada.

Dividimos esse artigo em quatro seções. Na primeira, apresentamos a Amazônia como espaço de sustentabilidade e discussão sobre o futuro do planeta. Na segunda, discutimos os problemas socioambientais que a Resex enfrenta e elucidamos a luta pela efetivação do manejo dos recursos naturais em terras públicas. Na terceira, refletimos sobre o trabalho realizado pelo IFT dentro da unidade de conservação na tentativa de fortalecer o tecido social para que o trabalho coletivo seja efetivo. E, por fim, na quarta analisamos o Marco Estratégico e as nuances de sua construção.

\section{Amazônia eterna: reflexões sobre desenvolvimento sustentável}

Sobre o modelo de sustentabilidade adotado para execução do Marco Estratégico, pautado na reflexão sobre a relação entre as populações humanas e o meio ambiente, Lima e Pozzobon (2005) explicam que durante os anos 1990 foi consolidado pela sociedade ocidental um referencial científico novo, com conceitos provenientes da ecologia e da teoria biológica da evolução, e com influências das propostas dos movimentos ambientalistas. Por sustentabilidade ecológica "entende-se a capacidade de uma dada população de ocupar uma determinada área e explorar seus recursos naturais sem ameaçar, ao longo do tempo, a integridade ecológica do meio

\footnotetext{
3 Conjunto de planejamentos e técnicas de colheita florestal, adaptadas às condições da floresta e aos objetivos sociais e econômicos do seu aproveitamento. O objetivo deste plano, exigido pela legislação florestal, é orientar a produção madeireira da floresta, assegurar um melhor aproveitamento dos recursos, aumentar a rentabilidade da atividade, reduzir o impacto da exploração, diminuir os riscos de trabalho e promover a sustentabilidade. O PMFS permite sintetizar o ambiente físico (clima, topografia, hidrografia, geologia, solo), socioeconômico (população, economia, infraestrutura) e biológico (vegetação e fauna). Disponível em: http://frmbrasil.com/produtos/gestao_naturais/pmfs.php
} 
ambiente" (LIMA e POZZOBON, 2005, p.1). Esse seria, então, o indicador mais importante para as análises realizadas no âmbito da diversidade social da Amazônia:

Se o critério de racionalidade econômica capitalista ordenava os segmentos sociais segundo seu grau de desenvolvimento e integração ao mercado, o emprego de critérios de sustentabilidade ecológica atribui a segmentos sociais antes inferiorizados uma valoração ecológica positiva. Esses mesmos segmentos sociais, como as populações indígenas, os seringueiros e os ribeirinhos, recentemente denominados "populações tradicionais", incorporaram a marca ecológica às suas identidades políticas como estratégia para legitimar novas e antigas reivindicações sociais. Dito de outra forma, o critério de valoração ecológica confere novas bases para uma valoração política dos segmentos sociais e engendra um novo quadro ordenatório da diversidade social da Amazônia (LIMA; POZZEBON, 2005, p.45).

Portanto, se as populações tradicionais passam a exercer papel fundamental na caracterização dos estudos sobre Amazônia, podendo assim legitimar suas reivindicações, acreditamos ser o momento de fortalecer os estudos que humanizam as atividades de planejamento desses grupos apresentando o protagonismo social deles. As vozes latentes que ecoam da floresta com reivindicações justas assumem novas vibrações e com o apoio de parcerias estão sendo direcionadas aos órgãos públicos de forma mais organizada.

Para Pressler, "a palavra Amazônia é permeada de significados, valores e sentidos que vão além de seu espaço geográfico nos diferentes discursos” (PRESSLER, 2012, p.33). Tais significados ganham espaço nos discursos a partir das mensagens propagandeadas pela mídia, por exemplo.

Com novos olhares sobre os critérios de valoração social, cujo referencial ambientalista está intrinsecamente associado, a Amazônia passa a estar inserida em um contexto mundial em que assume importância tanto científica quanto simbólica, sobretudo no imaginário da comunidade ecologizada no qual se apresenta como a maior floresta tropical remanescente do planeta aliada a outras questões oriundas do discurso ambientalista global, como a perda da diversidade biológica, efeito estufa e diminuição da camada de ozônio (LIMA e POZZOBON, 2005; PRESSLER, 2012).

A construção do paradigma ambientalista é resultado de uma longa reflexão sobre as raízes éticas e ideológicas da crise ambiental que põe em cheque diretamente o modelo de desenvolvimento capitalista, questiona o lugar da espécie humana na natureza e sua responsabilidade pelo futuro da biosfera. Esta autocrítica era, até recentemente, impensável (LIMA e POZZOBON, 2005, p.4546). 
Conforme frisa Pressler, "a imagem da Amazônia esteve sempre vinculada à temática ambiental" (PRESSLER, 2012. p.59). Para a autora, o mercado globalizado, o meio ambiente e a diversidade são as temáticas mais recorrentes sobre a Amazônia na contemporaneidade. E isto teria contribuído para a formação de um imaginário simbólico do que denota a concepção de Amazônia como um espaço exótico e outras enunciações que visam a destacar o deslumbramento do olhar estrangeiro sobre a imensidão verde desconhecida (PRESSLER, 2012). Nesse cenário, a Amazônia se destacaria, na contemporaneidade, pela degradação ambiental, pela natural grandiosidade e pela desigualdade social ainda com pouca cobertura científica desses temas (PRESSLER, 2012).

A partir da década de 1990, com o desenvolvimento sustentável em pauta, se destacam como principais temas de repercussão da Amazônia as políticas econômicas globalizadas. Pressler (2012) afirma que neste contexto histórico, a preservação da biodiversidade era meta global com amplo apoio da mídia, que tentava sensibilizar a opinião pública em torno do assunto. Foi neste período que surgiram as campanhas internacionais em defesa da Amazônia. Com a realização da Conferência das Nações Unidas sobre Meio Ambiente (CONUMA), globalmente conhecida como Rio 92, os ideais sobre desenvolvimento sustentável pautados nos discursos de ONGs e instituições internacionais, principalmente as europeias, ganharam destaque (PRESSLER, 2012). “Após esse momento, constata-se a construção de um campo ambiental transnacionalizado na Amazônia" (PRESSLER, 2012. P. 60).

Foi a partir da Rio 92 que o debate internacional sobre questões florestais obteve papel importante na agenda internacional. Portanto, o manejo dos recursos florestais passou a ter um tratamento abrangente, tornando-se requisitos de negociações internacionais importantes. (PRESSLER, 2012, p. 62).

Desde 1992, o Brasil participa das discussões sobre florestas no plano multilateral e defende sistemas florestais (tropicais, boreais e temperados) e no tratamento (econômico, comercial, social, cultural e ambiental) no manejo sustentável dos recursos florestais. A discussão sobre florestas é abrangente, uma vez que o assunto é relevante e, em especial, a conservação e o uso sustentável da biodiversidade; a promoção do desenvolvimento sustentável e a proteção dos recursos hídricos dentre outros tópicos inclusos nesse debate. (PRESSLER, 2012, p. 62-63).

A década de 1990 seria, portanto, um marco para o ingresso do Brasil no time das sociedades que passam a receber olhares com direito a uma análise ecológica: "o conceito de desenvolvimento sustentável, embora ambíguo e dotado de polissemia, coloca-nos à frente de um 
ideal de 'adaptação consciente"” (LIMA e POZZOBON, 2005, p. 45). Portanto, ao empregar o critério de sustentabilidade, Lima e Pozzobon (2005) afirmam que passamos a permitir que sejam conceituadas e enumeradas as diferentes formas de uso que as populações fazem do meio ambiente, levando em consideração as diversidade em termos de inserção na economia de mercado e os traços de uma tradição ou história ecológica.

É nesse cenário de fortalecimento de economia de mercado florestal sustentável que se fortalece o manejo florestal comunitário e a exploração de impacto reduzido. O planejamento é o princípio por trás do manejo florestal:

Manejo florestal é classicamente definido como aplicação de métodos empresariais e princípios técnicos na operação de uma propriedade florestal. Entre os princípios técnicos está a silvicultura como parte integrante do manejo. A silvicultura deve ser entendida como a parte da ciência florestal que trata do estabelecimento, condução e colheita de árvores. Esse conceito, que à primeira vista parece referir-se somente a florestas plantadas, aplica-se também a florestas naturais. Uma definição moderna de manejo se encontra no próprio decreto que regulamentou a exploração das florestas da Bacia Amazônica (Decreto n2 1.282, de 19.10.95). Neste documento, o termo manejo florestal sustentável é definido como administração de floresta para a obtenção de benefícios econômicos e sociais, respeitando-se os mecanismos de sustentação do ecossistema. Esta definição deixa claro que para ser sustentável, o manejo deve ser economicamente viável, ecologicamente correto e socialmente justo. O bom manejo inclui uma exploração cuidadosa (de baixo impacto ambiental), a aplicação de tratamentos silviculturais à floresta para regenerar e fazer crescer outra colheita, e o monitoramento, para ajudar o manejador na tomada de decisões técnicas e administrativas. (SILVA, 1996, p.11)

SILVA (1996) afirma que atender à legislação brasileira não é o único objetivo do plano de manejo florestal de um empreendimento. Pode ser incluído nesses objetivos, ainda, a continuidade da matéria-prima para abastecer o negócio, já que o manejo prevê vida longa à floresta em pé, ou seja, contribui para manutenção da qualidade da água, do ar, preservando a biodiversidade e gerando benefícios socioeconômicos.

\section{Sobre a Unidade de Conservação - Resex Verde para Sempre}

De acordo com Vieira e Vivacqua (2005):

as iniciativas de proteção da diversidade biológica voltadas para a criação de Unidades de Conservação no Brasil são tributárias da Convenção da Diversidade Biológica, assinada por ocasião da Cúpula da Terra em 1992. A criação e o controle de áreas protegidas de proteção integral e de uso sustentável são regulados pelas normas incorporadas ao Sistema Nacional de Unidades de 
Conservação (SNUC), instituído pela Lei 9.985/00. (VIEIRA E VIVACQUA, 2005, p. 139)

Estabelece-se, então, um marco para a criação e regulamentação da gestão das Unidades de Conservação. Há um claro esforço do governo brasileiro nos últimos 12 anos em estabelecer áreas de proteção. O próprio Instituto Chico Mendes de Conservação da Biodiversidade ICMBio, órgão responsável pela gestão destas áreas, esclarece que:

O Brasil, por abrigar a maior biodiversidade do mundo, tem uma responsabilidade muito grande nesta área. E por ser um dos países signatários da Convenção da Diversidade Biológica, assumiu o compromisso de destinar, sob a forma de Unidades de Conservação, 30\% do bioma Amazônia e 10\% dos demais biomas (Pampa, Pantanal, Caatinga, Cerrado e Mata Atlântica e os ecossistemas Marinhos e Costeiros), sendo computadas para isso também as UCs estaduais, municipais e particulares. (ICMBIO, 2015)

É neste cenário que encontramos a Reserva Extrativista - Resex Verde Para Sempre, Unidade de Conservação da modalidade Uso Sustentável, ou seja, a conservação da natureza está conciliada ao uso sustentável de parte dos seus recursos naturais. Foi criada em 2004, via decreto federal, possui área de 1.289.362,78 hectares e está localizada em sua totalidade territorial no município de Porto de Moz, estado do Pará (ICMBio, 2015). Porto de Moz está situado no Baixo Xingu, na mesorregião do Baixo Amazonas a $420 \mathrm{~km}$ de Belém. O principal acesso ao município é via fluvial, sendo Altamira o município de maior importância na região entorno.

Segundo informações do Instituto Brasileiro de Geografia e Estatística - $\mathrm{IBGE}^{4}$, o município possui área da unidade territorial de $17.423 \mathrm{Km}^{2}$ e uma população de 38.471 habitantes. Cerca de $80 \%$ do território municipal corresponde à Resex Verde Para Sempre. De acordo com o Instituto Chico Mendes de Conservação da Biodiversidade - ICMBio (2015), tratase da maior Unidade de Conservação do Brasil. Dados do IBGE (2000), apontam que a população da Reserva representa 42\% dos habitantes do município (10 mil habitantes), distribuídos em 57 comunidades e 37 localidades. A maioria desses habitantes concentra-se nas comunidades/localidades que se estabeleceram na área de transição entre os ambientes de várzea e de terra firme ou somente na várzea.

Segundo o IBGE (2010), o município de Porto de Moz produzia anualmente cerca de 1 tonelada de carvão vegetal, $2.261 \mathrm{~m}^{3}$ de lenha e $33.670 \mathrm{~m}^{3}$ de madeira em tora, sendo que a área

${ }^{4}$ Disponível em: http://cidades.ibge.gov.br/xtras/perfil.php?lang=\&codmun $=150590$ 
ocupada por estabelecimentos agropecuários em matas e/ou florestas naturais destinadas à preservação permanente ou reserva legal é de 250.465 hectares.

Segundo WATRIN e OLIVEIRA (apud BITTENCOURT, 2013), após mobilizações e lutas foi criada a Reserva Extrativista Verde para Sempre, motivada pela urgência de conter o avanço do desmatamento e a exploração predatória de madeira na região, além de garantir a regularização fundiária e permanência das famílias tradicionais no território ocupado por seus ancestrais. A criação da Resex Verde para Sempre diminuiu as ações dos agentes de conflitos em seu interior e iniciou uma nova fase de reestruturação da política ambiental nessa região junto às famílias, garantindo o direito de acesso e uso e a responsabilidade da gestão compartilhada de seus recursos naturais (BITTENCOURT, 2013).

As famílias residentes no interior da Resex desenvolvem atividades produtivas como a pesca artesanal, a agricultura de subsistência, a criação de animais, o extrativismo de sementes e frutos, a produção de óleos vegetais, resinas e artesanato de produtos não madeireiros. As principais fontes de renda das comunidades são a criação de búfalos em pequena escala, e a pesca, desenvolvidas nas áreas de várzea; e a roça tradicional, instalada nas áreas de terra firme (BITTENCOURT, 2013). Além desses produtos, a madeira tem um papel importante na economia de algumas das comunidades da Resex Verde para Sempre. A extração madeireira é uma prática local posterior à criação e delimitação física da unidade de conservação.

Em entrevista concedida no dia 30 de dezembro de 2015, o analista ambiental do ICMBio Carlos Eduardo Nascimento dos Santos, destaca informações sociais e políticas a respeito da Resex Verde Para Sempre, com foco na comunidade Itapéua:

Não há conflitos sociais que possam impedir a aprovação dos PMFS [Plano de Manejo Florestal Sustentável Comunitários. Pois estes devem ser discutidos e solucionados durante a elaboração dos regimentos internos dos grupos de manejadores. A demora para aprovação dos PMFS Comunitários desmotivou algumas pessoas. As comunidades estão sempre comprometidas em proteger suas Áreas de Manejo Florestal. A falta de oportunidades está ocasionando êxodo rural, principalmente dos mais jovens. As comunidades têm a madeira ilegal como fonte secundária de renda. Quem vende madeira ilegal teme ser pego pela fiscalização. E o preço de venda dessa madeira no mercado está muito aquém da legalizada. Existem anseios das associações que podem ser resolvidos com a aprovação dos planos. [...] Foi verificado que, devido ao maior tamanho de área destinada ao manejo florestal, a comunidade Itapéua apresenta a maior relação hectare / $\mathrm{n}^{\mathrm{o}}$ de famílias (708,64 ha /família). Quanto a este tema no relatório foi levantado o questionamento sobre qual o número de ótimo de famílias por unidade de área a ponto de satisfazer as necessidades individuais e coletivas sem ao mesmo tempo superexplorar o trabalho e a capacidade de 
trabalho dos manejadores. Em todas as comunidades, incluindo Itapéua, foi verificada a pouca participação de mulheres e jovens. Tal fator é fundamental para que a "engrenagem" continue funcionando a longo prazo. Uma vez que os jovens são os responsáveis pela renovação da força de trabalho e as mulheres podem ser as responsáveis pelas atividades para melhoria das condições de trabalho do grupo de manejadores com a organização de materiais e alimentação. Quanto à participação efetiva, dos 30 associados da comunidade Itapéua, 11 foram declarados com efetivamente participando. Observa-se que em todas as comunidades foi dito que, com a aprovação dos PMFS Comunitários, este número aumenta. (SANTOS, 30/12/2015).

Dados levantados pelo IFT (2013) apontam para a necessidade e urgência das populações tradicionais residentes na Resex Verde Para Sempre, além dos próprios movimentos sociais que atuam na região, para que o manejo florestal se estabelecesse como uma atividade econômica legalmente reconhecida e apoiada pelo ICMBio. A luta pela efetivação da atividade na região fez com que o instituto criasse, em 2011, uma Instrução Normativa que simplificasse o licenciamento do manejo florestal para fins madeireiros em Resex, Floresta Nacional (Flona) e Reserva de Desenvolvimento Sustentável (RDS), a IN 11/2016. Embora seja um avanço para a consolidação do manejo florestal como atividade econômica, reconhecida e regulamentada pelo órgão, muitos sãos os fatores que podem impedir a implementação da atividade, entre elas a falta de conhecimento técnico, tanto por parte do ICMBio, quanto pelas comunidades.

MARTINS et al. (2007), em estudo de avaliação da pressão humana sofrida na região após a assinatura do decreto que instituiu a Reserva, apontam para a continuidade do desmatamento dentro da área da Reserva:

Considerando que objetivos elementares de uma Resex são de proteger os meios de vida e a cultura das populações tradicionais, e assegurar o uso sustentável dos recursos naturais IBAMA (2006). Em relação a Resex Verde para Sempre, analisada neste estudo, tais objetivos podem estar sob ameaça, visto que, mesmo após a sua criação o desmatamento e do número de focos de calor ainda persistem, a pesar de uma diminuição de suas taxas. Em relação às estradas, apresentaram um considerável crescimento tanto no entorno como no interior da Resex, aumentado assim a sua fragilidade em relação às atividades predatórias.

Os dados sugerem que as atividades predatórias dentro e no entorno da Resex continuam (apesar da redução das taxas de desmatamento) e tendem aumentar, visto que a abertura de estradas aumentou, mesmo depois do decreto de criação da reserva. Considerando que o estudo analisa somente os dados do primeiro semestre de 2006 e que abertura de estradas é o sinal claro que o acesso ao interior da Reserva continua, pode-se prever um cenário mais preocupante para o próximo ano. Desta forma, sugere-se que medidas de controle e fiscalização sejam adotadas, tais como demarcação, instalação de posto de fiscalização e 
monitoramento espacial constante, especialmente na parte sul da Reserva (MARTINS et al, 2007, p. 2823)

Apesar da data da avaliação estar distante, ainda em 2015 foi possível encontrar a preocupação entre os moradores da Resex com o desmatamento realizado por empresas madeireiras ou pequenos negócios florestais que retiram madeira ilegal da Unidade, como expressa o presidente da Associação de Desenvolvimento Sustentável dos Produtores Agroextrativista da Comunidade Itapéua, Evandro de Almeida Pinheiro, no dia 11 de novembro de 2015:

Estamos aqui dentro lutando para conquistar o manejo, nos articulando com poder público e com instituições não-governamentais enquanto vemos a madeira passar aqui na frente da nossa comunidade em grandes balsas. Eles dizem que é madeira de áreas aqui próximas, que tem plano de manejo empresarial, mas a gente sabe que nem sempre é de lá. Quando andamos pela mata vemos que eles ainda tiram madeira aqui de dentro e nós que somos os moradores tradicionais temos que passar por tanta burocracia. (PINHEIRO, 11/11/2015).

O IFT, que atua há 21 anos com capacitação e treinamento em manejo florestal e exploração de impacto reduzido, afirma, em projeto apresentado ao Fundo Vale de Conservação da Biodiversidade, que a existência de poucos exemplos de manejo florestal comunitário estabelecidos na Amazônia e a falta de modelos replicáveis que possam auxiliar os processos de tomada de decisão também se apresenta como um entrave. No documento, o IFT explica que as populações da Resex estão expostas a um baixo nível de apoio em termos de implementação das políticas públicas, e segue afirmando que enquanto o órgão ambiental responsável pela gestão ICMBio - não assumir, de fato, papel de fomentador de atividades econômicas sustentáveis, os objetivos pelos quais a unidade de conservação foi criada não serão atingidos, ocasionando sérios riscos de perda de biodiversidade, perda da identidade tradicional e meios para reprodução cultural, social, religiosa, ancestral, econômica e histórica destas populações (IFT, 2013).

Os produtos comunicacionais, como o Marco Estratégico, oriundos da parceria entre IFT e comunidades, contêm reflexões sobre o passo a passo dado pelo Projeto Jutaí para efetivação da atividade de exploração madeireira sustentável na Resex e a reflexão coletiva sobre o papel do grupo de manejadores - expressão alcunhada pelas entidades ambientais que atuam com manejo florestal para identificar indivíduos que atuam com a exploração florestal - na gestão do "negócio" florestal pode ser uma oportunidade ao governo, comunidades e sociedade civil 
organizada se debruçarem sobre as necessidades das comunidades que almejam ter a atividade legalmente reconhecida pelo mercado, assegurando renda, geração de trabalho para jovens e adultos, benefícios coletivos e, consequentemente, direitos sociais e conservação da biodiversidade amazônica.

\section{Marco Estratégico: reflexão coletiva e o olhar para o futuro}

Em 2014, o IFT assumiu outras nuances da conservação florestal e passou a investir esforços no fortalecimento da organização social para a efetivação do manejo florestal comunitário em áreas de proteção ambiental. Foi nesse ano que a instituição teve o Projeto de Apoio ao Desenvolvimento do Manejo Florestal Comunitário e Familiar em Florestas Públicas da Amazônia Brasileira aprovado para financiamento pelo Fundo Vale de Conservação da Biodiversidade. O projeto, entre outras Resex, abrangia a Verde Para Sempre.

O IFT percebeu que existia na Verde Para Sempre um anseio em usar racionalmente os recursos naturais e, inclusive, um interesse das comunidades em estabelecer cadeias de valor para os principais produtos com os quais os já trabalhavam em escala familiar. Contudo, as dificuldades encontradas por moradores da floresta ocasionavam forte erosão das tradições e a migração para as cidades em busca de sobrevivência. O cenário era desfavorável a implantação do manejo florestal pois, além de desmotivados, os comunitários possuíam pouco conhecimento sobre os trâmites legais. A partir desta premissa, técnicos e comunitários passaram a discutir um novo modelo de atuação, pautado na troca de conhecimentos e fortalecimento de competências que incluía dentre as atividades o desenvolvimento do Marco Estratégico do Projeto Jutaí.

De acordo com Ana Luiza Violato Espada, coordenadora do Programa de Manejo Florestal Comunitário e Familiar do IFT, em entrevista realizada no dia 06 de fevereiro de 2016 por e-mail, o Marco Estratégico é "um planejamento estratégico-organizacional que trabalha noções de coletivismo, princípios e diretrizes organizacionais a partir da visão das comunidades em relação aos objetivos finalísticos do desenvolvimento do manejo florestal comunitário" (ESPADA, 06/02/2016).

Devido à necessidade de fortalecer a organização social e institucional nas comunidades para a realização do manejo florestal, o IFT desenvolveu a iniciativa do Marco Estratégico. De acordo com César Haag, consultor contratado pelo IFT para elaborar a metodologia da atividade, 
em entrevista realizada no dia 24 de fevereiro de 2015 por e-mail, todo planejamento deve partir da definição daquilo que é estratégico, para depois pensar no operacional. Portanto, seria um movimento natural do raciocínio definir os objetivos e depois implementar ações para atingi-los. Ações que não são alinhadas aos objetivos contribuem pouco aos fins. Portanto, o Marco Estratégico seria um processo de reflexão daquilo que são os objetivos maiores das ações das comunidades em prol do manejo florestal (HAAG, 2015).

Segundo HAAG, em síntese, o Marco Estratégico é um norte, uma diretriz maior que guiará as ações e tomadas de decisões das comunidades durante as atividades relacionadas ao manejo florestal ou que dele derivam (HAAG, 2015). César lembra que foram adaptados alguns conceitos de planejamento tradicionalmente utilizados pelo setor privado e que são adotados por diversas instituições e outros coletivos, gerando resultados positivos:

Foi possível ajudá-los a construir a missão, visão de futuro, valores e público alvo, além de resgatar a história da relação entre as comunidades e o trabalho com a floresta. São conceitos simples, mas que geram uma reflexão em grupo interessante e serão de grande valia para o futuro. Com certeza este trabalho será visitado pelos manejadores muitas vezes [...] Já trabalhei direta ou indiretamente com mais de 60 Unidades de Conservação na Amazônia. Esta trajetória me fez observar e ter contato com diferentes níveis de prosperidade entre as comunidades com que trabalhei. Normalmente os maiores níveis de prosperidade se encontram em comunidades mais organizadas. Parece haver uma relação diretamente proporcional entre prosperidade e organização (HAAG, 24/02/2015).

Ana Luiza Violato conta que o cenário em que o Marco foi estabelecido na agenda de atividades do projeto em que a comunidade Itapéua estava inserida foi favorável à aplicação. Segundo ela, foi percebida a necessidade dos manejadores se organizarem como grupo, como coletivo, para trabalharem juntos o manejo florestal comunitário. A finalidade era fortalecer a organização social (pessoas) e institucional (associações e cooperativas) e dar visibilidade aos projetos e empreendimentos comunitários que surgiriam, atraindo com isso, mais parceiros (VIOLATO, 2016).

\section{A operacionalização do Marco Estratégico}

O Marco Estratégico do Projeto Jutaí foi construído ao longo de onze meses, entre a primeira reunião para apresentação da metodologia, ocorrida entre os dias 25 de janeiro e 08 de fevereiro de 2015, à entrega do produto final aos manejadores, realizada entre os dias 12 e 13 de 
janeiro de 2016. No total, foram realizados três encontros com os manejadores dentro da Resex, na escola da comunidade Itapéua.

Cerca de três colaboradores do corpo técnico do IFT estiveram presentes nos encontros que desenvolveram o Marco Estratégico, revezando-se nas funções de mediador dos diálogos entre os manejadores e facilitador das atividades. Todos ficavam hospedados na escola infantil onde as atividades eram realizadas e planejavam uma logística que incluía a alimentação para os dias em que ficariam em campo e todo equipamento necessário para execução da atividade, como projeto de slides e material pedagógico.

$\mathrm{Na}$ primeira reunião, intitulada "I Oficina para construção dos instrumentos sociais do manejo florestal comunitário", ocorrida em fevereiro de 2015, participaram 21 moradores. Na ocasião, foram levantadas algumas informações essenciais sobre a comunidade para que se entendesse o contexto organizacional da associação comunitária. Informações estas que o engenheiro de projetos do IFT, Wallacy Ferreira Barreto, considera que seriam relevantes na construção do Marco Estratégico. Tais informações foram relatadas em entrevista realizada no dia 20 de dezembro de 2015:

Realizamos dinâmica para elencar sugestões de nomes para o projeto e a dinâmica "telefone sem fio" para fomentar a realização de reuniões periódicas da associação. Apresentação do Observatório Florestal $^{5}$ como ferramenta de acompanhamento das atividades do projeto e espaço para dar publicidade às atividades desenvolvidas por eles no manejo florestal. Realização de dinâmicas para construção do briefing que vai auxiliar a produção da logomarca do projeto. Foi realizada entrevista com Evandro de Almeida Pinheiro, 47 anos, presidente da associação de moradores. Ele contou sobre a luta pela regulamentação da atividade e as dificuldades para garantir a comunidade de pé. Nesta ocasião confirmamos os dados de localização da comunidade. Propostas de nomes para o projeto de MFC, que foram: Jutaí; Magro e Nú; Itapéua. Os mais votados foram: Pinheiro-Aragão; Jutaí; Ipê-Roxo; e El Shadai. Os comunitários adultos muito participativos. Há muitos jovens, sobretudo mulheres, mas que se demonstraram pouco interessados em participar das atividades referentes ao projeto de manejo. $\mathrm{Na}$ escola há computadores, impressora, gerador de energia, dois telefones públicos. A igreja exerce poder sobre o cotidiano. (BARRETO, 20/12/2015).

A intervenção na comunidade se deu da seguinte forma: dinâmica de abertura e boas vidas, com rodada de apresentações em forma de gestos, onde cada participante da oficina se

\footnotetext{
${ }^{5}$ No formato de blog, - www.ift.org.br/observatorio-florestal/ - o Observatório Florestal é uma plataforma on-line para produção de conhecimento, divulgação e disseminação de textos, áudios e vídeos sobre as boas práticas do manejo florestal comunitário e familiar na Amazônia. O espaço é, sobretudo, uma ferramenta de registro dos avanços do Programa de Manejo Florestal Comunitário e Familiar nos territórios de atuação do IFT.
} 
apresentou dizendo seu nome e fazendo um gesto que o representava. Desta forma, todos os participantes repetiram os gestos dos demais, em momento lúdico de integração. Foi realizada, também, narrativa oral sobre o processo de elaboração do Marco Estratégico.

No retorno da equipe do IFT, realizado nos dias 11 e 12 de novembro de 2015, foi realizada a atividade intitulada "II Oficina para construção dos instrumentos sociais do manejo florestal comunitário", e a construção do Marco Estratégico estava na programação. Durante dois dias foram reservados momentos para que os moradores refletissem sobre o grupo e desenvolvessem textualmente a missão, os valores, visão de futuro e público-alvo do Projeto Jutaí - aliás, o nome do projeto foi escolhido e consolidado nesse mesmo encontro durante votação entre os presentes. Os manejadores foram divididos em dois grupos de trabalho para que pudessem obter vozes plurais nos conceitos do Marco. Um grupo se encarregou de refletir sobre o nome do projeto, o logotipo e a missão, o segundo de construir a "Visão de futuro", "Valores" e "Público-alvo", cerca de oito pessoas participaram de cada grupo. Os resultados dessa atividade serão expostos no tópico seguinte. Participaram da oficina 17 pessoas.

É importante ressaltar que neste mesmo encontro também foi consolidada a Matriz F.O.F.A ${ }^{6}$ (análise SWOT) e iniciou-se a construção do Regimento Interno do Manejo Florestal Comunitário, ambas atividades compuseram um cenário em que os comunitários já estavam imersos: uma experiência voltada para si mesmos, vinda da construção do Marco Estratégico, conforme observamos no depoimento do presidente da Associação, Evandro Almeida realizado no dia 11 de novembro de 2015:

Não estamos acostumados a pensar sobre esse tipo de coisa como falar sobre nossa visão de futuro ou sequer pensar que temos uma missão. Quando realizamos esse tipo de atividade podemos perceber que olhar para si, para o outro e para nossa comunidade, é fundamental para o sucesso do projeto. Somos muito bons em tirar o pau de uma árvore, em abrir trilhas e até planejar nossas idas para campo, mas quando passamos pra esse lado da gestão é mais difícil. Pensar no regimento e nas nossas fortalezas, ameaças e essas coisas fica mais fácil quando estamos unidos e com a cabeça alinhada na mesma missão (ALMEIDA, 11/11/2015).

\footnotetext{
${ }^{6}$ Instrumento de análise de negócio simples e valioso. Sua finalidade é detectar pontos fortes e fracos de uma empresa, com o objetivo de torná-la mais eficiente e competitiva, corrigindo assim suas deficiências. O nome é um acrônimo para Forças, Oportunidades, Fraquezas e Ameaças. Também conhecida como análise F.O.F.A. ou análise F.F.O.A, a matriz deriva da análise SWOT (Strenghts, Weaknesses, Opportunities e Threats). Realizar uma análise F.O.F.A. leva a empresa a pensar nos aspectos favoráveis e desfavoráveis do negócio, dos seus proprietários e do mercado. Disponível em: http://www.sebrae.com.br/sites/PortalSebrae/artigos/Use-a-matriz-F.O.F.A.-para-corrigir-defici\%C3\%AAncias-e-melhorar-aempresa
} 
A II Oficina para construção dos instrumentos sociais do manejo florestal comunitário foi realizada nos dias 12 e 13 de janeiro de 2016. Neste encontro participaram 17 comunitários. Foram apresentados o logotipo do Projeto Jutaí e o documento final do Marco Estratégico aprovado em votação em plenária.

A missão do Projeto Jutaí, segundo documento em que constam os conceitos do Marco Estratégico, disponibilizado pelo IFT, é o propósito ou a razão de existência do projeto de manejo florestal. Serve como diretriz geral para orientar a tomada de decisão e auxiliar nas escolhas das melhores estratégias e deve sempre ser visitada para que o projeto de manejo florestal não perca o foco de suas responsabilidades essenciais.

Os manejadores definiram que, para eles, a missão do projeto é: "Realizar o manejo florestal comunitário legalizado, agregar valor à produção florestal, contribuir com a conservação de nossa floresta e dar continuidade às nossas tradições” (MARCO ESTRATÉGICO..., 2015). "Essa é uma missão de vida, que já levamos conosco desde que nascemos. Agora, com ela no papel e dividida com todo mundo, podemos olhar pra frente em unidade", explicou em entrevista o manejador Braz Rodrigues de Aragão (ARAGÃO, 11/11/2015).

A Visão de Futuro, segundo o IFT (2015) expressa a situação ideal para os comunitários no prazo de 10 anos. "Seria a forma como imaginam a realidade das comunidades com as transformações positivas que o projeto de manejo florestal poderá gerar. Pensar nas conquistas, nas melhorias, nos benefícios que o projeto de manejo florestal pode trazer" (IFT, 2015). Na descrição, a instituição ressalta que devem ser situações desejáveis, ideais e possíveis de serem realizadas em dez anos.

Como visão de futuro, os manejadores estabeleceram:

No futuro, o Projeto Jutaí de manejo florestal comunitário será gerenciado pelos próprios manejadores. O Projeto vai possibilitar a construção do posto de saúde e escola de ensino fundamental e médio. A comunidade Itapéua terá uma boa infraestrutura, além de transporte adequado para as pessoas e para o escoamento da produção agroflorestal. A associação estará fortalecida e a produção agrícola será diversificada. Faremos o manejo florestal de diversos produtos como: madeira, açaí e outros produtos florestais não madeireiros. (MARCO ESTRATÉGICO..., 2015).

Os valores são os princípios éticos e morais fundamentais e permanentes do projeto. Representam as convicções e crenças básicas, aquilo em que a maioria das pessoas do projeto de manejo florestal acreditam ser valores fundamentais. Os valores devem ser respeitados pelas 
pessoas que participam do projeto de manejo florestal, contribuindo para a unidade entre os membros e coerência do trabalho (IFT, 2015).

Sendo assim, os valores apontados pelo grupo, foram:

Responsabilidade: cada manejador é responsável pela função e tarefa que lhe é atribuído; Participação: cada manejador pode colaborar e dar sua opinião nas discussões e tarefas de campo e toda decisão será baseada respeitando a opinião de todos; União: a união rompe todos os obstáculos, todos desejam a mesma coisa e lutam por ela; Respeito: cada manejador tem seu valor, e ninguém é maior que o outro. O respeito começa em cada um de nós e o trabalho do companheiro deve ser valorizado. É preciso ouvir e respeitar a opinião de todos, concordando ou discordando, mas chegando ao acordo comum; Igualdade: Todos têm direito às mesmas condições para melhorar a qualidade de vida e buscaremos a igualdade de gênero, todos podem trabalhar, homem e mulher; Transparência e honestidade: as informações serão compartilhadas com todos, manejadores e parceiros, e seremos honestos para receber e pagar por aquilo que realmente trabalhamos; Dignidade: trabalharemos na legalidade, sendo respeitados, com honestidade e sinceridade; Fé, perseverança e paciência: acreditamos naquilo que não vemos, mas temos a convicção de que pode acontecer. E vamos insistir em nossos propósitos até atingir nossos objetivos lutando e acreditando, com paciência e muita fé (MARCO ESTRATÉGICO..., 2015).

O público-alvo, para o IFT (2015), são grupos de pessoas, classes ou entidades que se envolvem ou são favorecidos com os resultados do projeto de manejo florestal. O público-alvo pode ser direto ou indireto, de acordo com seu grau de participação ou envolvimento no projeto de manejo florestal. O grupo de manejadores definiu como público-alvo os seguintes segmentos:

Comunidade Itapéua; comunidades vizinhas; associados; manejadores; ICMBio; IBAMA; juventude da comunidade; instituições parceiras (ONGs); prefeitura municipal de Porto de Moz; Conselho Deliberativo da Resex; Resex Verde para Sempre; outras Reservas Extrativistas; Bancos e instituições de financiamento; moveleiros; estaleiro; marceneiros; e serrarias. (MARCO ESTRATÉGICO..., 2015).

O histórico foi construído durante entrevistas com Evandro de Almeida Pinheiro e Braz Rodrigues de Aragão, escrito pela equipe do IFT e aprovada durante encontro com os comunitários na Resex. Segue:

A comunidade Itapéua está localizada na Reserva Extrativista (Resex) Verde para Sempre, em Porto de Moz, no Pará. A Resex é uma Unidade de Conservação de Uso Sustentável, ou seja, a conservação da natureza é conciliada com o uso sustentável dos recursos naturais. Com mais de um milhão de hectares de área protegida, a Resex faz parte do bioma Amazônia. Nesta Resex vivem aproximadamente 2600 famílias distribuídas em 58 comunidades e 31 
localidades. Os moradores desenvolvem atividades de pesca, extrativismo e agricultura familiar. Outra prática produtiva que ocorre na Reserva é a criação de búfalos: são mais de 30 mil cabeças, que sustentam a produção de queijo e leite. O manejo florestal comunitário é uma das atividades econômicas da Resex Verde para Sempre e o Projeto Jutaí é uma iniciativa dos moradores da comunidade Itapéua, localizada no rio Jaurucu. A finalidade do Projeto Jutaí é reunir esforços para utilizar os recursos florestais de maneira consciente para a sustentabilidade ambiental, econômica e social. O Projeto nasceu dos esforços da Associação de Desenvolvimento Sustentável dos Produtores Agroextrativistas da Comunidade Itapéua e conta com o apoio de vários parceiros. Na comunidade Itapéua, o uso dos recursos florestais é realizado por populações tradicionais há gerações, os moradores recordam da prática de exploração madeireira em pequena escala desde a década de 1970. Com empenho e compromisso os manejadores e as manejadoras da comunidade Itapéua se organizaram para garantir o direito de uso dos recursos naturais da Resex Verde para Sempre e usufruir dos recursos disponíveis para garantir a própria existência. (MARCO ESTRATÉGICO..., 2015)

O processo de construção do Marco Estratégico na Resex Verde para Sempre foi realizado de modo dialogado com os moradores da reserva e os especialistas do IFT. Isso estimulou que os moradores embasassem as decisões tomadas tanto no conhecimento empírico quanto no especializado e apontassem estratégias de articulação e organização da comunidade que definiram normas de convivência e regras de uso e distribuição dos recursos oriundos do manejo florestal comunitário, por exemplo.

\section{Considerações finais}

Ainda é cedo para analisar os resultados da aplicação do Marco no grupo de manejadores. O processo é recente e os resultados poderão ser visíveis a partir do segundo ou terceiro ano de execução do manejo florestal. Porém, o processo proporcionou reflexões sobre o papel do manejo florestal nas florestas comunitárias e a visibilidade dos grupos de manejadores, pois foram produzidos folders que reúnem as reflexões apresentadas na forma de missão, visão, valores e outros, que diferentes públicos (governo, empresas, ONGs) podem acessar. O IFT atua apenas como mediador do processo, tudo que é produzido vem da reflexão coletiva sobre o papel do manejo florestal comunitário, por isso, a participação dos moradores é essencial.

Segundo Ana Luiza, "os comunitários, quando instigados, produzem reflexões importantes para o coletivo. O processo de definição dos valores do grupo é algo que surte efeito para o que é um trabalho coletivo, em que não existe patrão, e que o respeito é a base de tudo" 
(ESPADA, 2016). A atividade de construção do Marco resultou na importância de estabelecer fundamentos para o trabalho em grupo, como o documento intitulado Regimento Interno do Manejo Florestal Comunitário do Projeto Jutaí, que além das regras de admissão e demissão dos manejadores, por exemplo, também estabelece como os benefícios financeiros serão utilizados. Trata-se de um olhar de si, para si. Baseados na missão e visão de futuro, descritos no Marco Estratégico, os moradores podem definir como aplicar o dinheiro. Em suma, o Marco trouxe organização para o trabalho coletivo e mais sentimento de pertencimento ao ser manejador e fazer parte de um processo coletivo. Sobre este cenário, o presidente da associação, Evandro de Almeida Pinheiro, afirmou que:

\begin{abstract}
Algumas famílias saíram da comunidade, hoje somos cerca de 11 pessoas envolvidas diretamente no manejo. Nascemos e nos criamos na região. Viemos pro Itapeuá quando eu tinha 13 anos de idade. Fundamos a associação para organizar a luta. Hoje em dia nossos filhos estão lutando ao nosso lado, minha esposa trabalha na escola da comunidade com canteiro sustentável, tenho dois filhos que são professores. Nossa escola vai até a oitava, quem quer estudar tem que sair. Desde 2012, estamos trabalhando para trazer o ensino médio, mas falta casa para o professor trabalhar. Com o plano aprovado vai mudar muita coisa por aqui. Com a criação de um documento que mostre quem somos e o que queremos, como é esse Marco, vamos poder sair daqui com ele em mãos e nos apresentar como grupo organizado, com um nome, uma história que não começou agora. (PINHEIRO, 11/11/2015, grifo nosso).
\end{abstract}

Em fevereiro de 2015, o ICMBio aprovou o Plano de Manejo Florestal Sustentável. O próximo passo para garantir a exploração florestal na Resex Verde para Sempre é a aprovação do Plano Operacional Anual (POA) e a liberação da Autorização de Exploração (Autex). Enquanto aguardam os trâmites legais dos documentos que vão garantir legitimação para a atividade florestal, os comunitários participam de ações que visam a fortalecer as relações de solidariedade e dar subsídios para que as entidades detentoras dos PMFS estejam capacitadas como gestoras, a fim de darem seguimento às etapas do manejo florestal e da cadeia de valor da madeira. Concluímos que o modelo do Marco Estratégico mostra-se, apesar de inicial, promissor em relação às possibilidades de sustentabilidade da floresta e dos povos tradicionais que nela habitam. 


\section{REFERÊNCIAS}

AMARAL, Paulo Henrique Coelho; MARTINS, Heron David dos Santos; NASCIMENTO, Katiuscia Amanda Fernandes de; REIS, Rodney Rooney Salomão. Avaliação da pressão humana na Reserva Extrativista Verde para Sempre no oeste do Pará. In: SIMPÓSIO BRASILEIRO DE SENSORIAMENTO REMOTO, XIII, Florianópolis, Brasil, 21-26 abril 2007, Anais, INPE, p. 2817-2824. Disponível em <http://marte.sid.inpe.br/col/dpi.inpe.br/sbsr@80/2006/11.14.20.56/ doc/2817-2824.pdf>. Acesso em: 12 fev. 2016.

BITTENCOURT, Paulo Gama. Plano de Manejo Florestal Sustentável da Associação de Desenvolvimento Sustentável dos Produtores Agroextrativista da Comunidade Itapéua. Porto de Moz, 2013.

INSTITUTO BRASILEIRO DE GEOGRAFIA E ESTATÍSTICA -IBGE.Cidades@-PA-Porto de Moz. 2010. Disponível em: <http://cidades.ibge.gov.br/xtras/perfil.php?lang= \&codmun=150590>. Acesso em: 6 fev. 2016.

INSTITUTO CHICO MENDES DE CONSERVAÇÃO DA BIODIVERSIDADE - ICMBio. Unidades de Conservação: Bioma Amazônia. 2015. Disponível em:

<http://www.icmbio.gov.br/portal/biodiversidade/unidades-de-conservacao/biomasbrasileiros/amazonia/unidades-de-conservacao-amazonia/2007-resex-verde-parasempre.html?highlight=WyJ2ZXJkZSIsInZlcmR1JyIsInBhcmEiLCIncGFyYSIsInBhclx1MDBIM SciLCJzZW1wcmUiLCJ2ZXJkZSBwYXJhIiwidmVyZGUgcGFyYSBzZW1wcmUiLCJwYXJhI HNlbXByZSJd>. Acesso em: 12 fev. 2016.

INSTITUTO DE PESQUISA ECONÔMICA E APLICADA - IPEA. O que é Oscip? 2016. Disponível em: <http://desafios.ipea.gov.br/index.php?option=com_content\&view=article\&id $=2054$ : catid=28\&Itemid=23>. Acesso em: 8 fev. 2016 .

INSTITUTO FLORESTA TROPICAL -IFT. Conceitos do Marco Estratégico. Belém: IFT, 2015

INSTITUTO FLORESTA TROPICAL -IFT. Informativo Técnico 1 - Manejo florestal e exploração de impacto reduzido em florestas naturais de produção na Amazônia. Belém: IFT, 2013. Disponível em: <http://ift.org.br/wp-content/uploads/2014/11/InformativoT\%C3\%A9cnico-1.pdf >. Acesso em: 9 fev. 2016.

LIMA, Deborah; POZZOBON, Jorge. Amazônia socioambiental: sustentabilidade ecológica e diversidade social. Estudos Avançados, São Paulo, v. 19, n. 54, p. 45-76, Ago. 2005.

Disponível em: <http://www.scielo.br/scielo.php?script=sci_arttext\&pid=S0103$40142005000200004 \& \operatorname{lng}=e n \& n r m=i s o>$. Acesso em: 9 fev. 2016.

MARCO ESTRATÉGICO DO PROJETO JUTAÍ. Associação de Desenvolvimento Sustentável dos Produtores Agroextrativista da Comunidade Itapéua. Porto de Moz: ADESPAC, 2015. 
PRESSLER, Neusa. Comunicação e Meio Ambiente: Agência de Cooperação Internacional e Projetos Socioambientais na Amazônia. Belém: Unama; Manaus: UEA, 2012.

SILVA, José Natalino Macedo. 1996. Manejo florestal. 2 ed. Brasília: Embrapa/ SPI, 1996. 46p. Disponível em:

<https://www.infoteca.cnptia.embrapa.br/bitstream/doc/916225/1/ManejoFlorestal.pdf>. Acesso em: 9 fev. 2016.

VIVACQUA, Melissa; VIEIRA, Paulo Freire. Conflitos socioambientais em Unidades de Conservação. Política e Sociedade, Florianópolis, v. 4, n. 7, p. 139-162, out. 2005. Disponível em: < https://periodicos.ufsc.br/index.php/politica/article/view/1970/1720>Acesso em: 12 fev. 2016.

\section{Entrevistas}

ARAGÃO, Braz Rodrigues. Entrevista concedida a Elias Santos Serejo. Porto de Moz, 11 de nov. 2015. [entrevista concedida oralmente e gravada em áudio]

BARRETO, Wallacy Ferreira. Entrevista concedida a Elias Santos Serejo. Belém, 20 de dez. 2015. [entrevista concedida oralmente via telefone]

ESPADA, Ana Luiza Violato. Entrevista concedida a Elias Santos Serejo. Belém, 6 fev. 2016. [entrevista realizada via e-mail]

HAAG, César. Entrevista concedida a Elias Santos Serejo. Belém, 24 fev. 2015 [entrevista concedida via e-mail]

PINHEIRO, Evandro de Almeida. Entrevista concedida a Elias Santos Serejo. Porto de Moz, 11 de nov. 2015. [Entrevista concedida oralmente e gravada em áudio]

SANTOS, Carlos Eduardo Nascimento. Entrevista concedida a Elias Santos Serejo. Belém, 30 de dez. 2015. [entrevista concedida via e-mail] 